Research Article

\title{
Enhanced Mechanical and Microstructural Properties of Portland Cement Composites Modified with Submicron Metakaolin
}

\author{
Yaoyu Wang $\mathbb{D}^{1},{ }^{1}$ Jiye $\mathrm{Li}^{2}{ }^{2}$ Lihan Jiang, ${ }^{3}$ and Lihua Zhao $\mathbb{i D}^{4}$ \\ ${ }^{1}$ Institute of Road and Bridge Engineering, Dalian Maritime University, Dalian, Liaoning 116026, China \\ ${ }^{2}$ College of Civil Engineering, Dalian Minzu University, Dalian 116650, China \\ ${ }^{3}$ Institute of City, Dalian University of Technology, Dalian, Liaoning 116600, China \\ ${ }^{4}$ Institute of Civil Engineering, Dalian Jiaotong University, Dalian, Liaoning 116028, China
}

Correspondence should be addressed to Lihua Zhao; zhaolihua1015@126.com

Received 27 September 2020; Revised 13 December 2020; Accepted 19 December 2020; Published 30 December 2020

Academic Editor: José Aguiar

Copyright (C) 2020 Yaoyu Wang et al. This is an open access article distributed under the Creative Commons Attribution License, which permits unrestricted use, distribution, and reproduction in any medium, provided the original work is properly cited.

\begin{abstract}
This work aims to study the influence of submicron metakaolin (SMK) on the mechanical strength, pore structure, and microstructural properties of hardened cement-based slurry (HCS). Portland cement was replaced by SMK at a proportion of $1,3,5$, and $7 \mathrm{wt} \%$. The compressive strength and flexural strength of the HCS samples were tested at a curing period of 3, 7, 14, and 28 days, and the pore structure of the specimens was analyzed by mercury intrusion porosimetry (MIP) at a curing period of 3 and 28 days. The microstructure characteristics of the hardened samples were investigated by scanning electron microscopy (SEM) and energy dispersive X-ray spectroscopy (EDS). Thermogravimetric analysis (TGA) was also employed to analyze the change in the chemical composition of the HCS. The results showed that the SMK could accelerate the hydration rate of the cement and could improve the mechanical properties of the HCS; the compressive strength and flexural strength of the HCS samples were remarkably enhanced, compared to those of the plain cement, by 67 and 46\%, respectively, at a curing period of 3 days and by 33 and $35 \%$, respectively, at a curing period of 28 days. The SMK had a significant impact on the internal pore structure of the hardened samples, and the number of pores with a diameter of larger than $3000 \mathrm{~nm}$ significantly decreased. Because the hydration products filled the pores, the microstructure of the HCS was further refined and densified with the addition of SMK. Submicron metakaolin has a simple process and high activity, which can significantly improve the performance of the cement slurry. Therefore, submicron metakaolin has the potential for practical engineering applications.
\end{abstract}

\section{Introduction}

As the urbanization and technicalization are increasing, the world demand for cement as the most consumed manufactured substance in construction is also increasing. Cement production accounts for $8 \%$ of the global emissions of carbon dioxide $\left(\mathrm{CO}_{2}\right), 40 \%$ of which results from burning fossil fuels and the rest from the calcination of limestone [1-4]. A solution to reduce the amount of cement used and thus the emission of $\mathrm{CO}_{2}$ [5] is to partially replace cement with natural and artificial pozzolanic materials such as mineral powder, fly ash, silica fume, zeolite powder, montmorillonite, and metakaolin [6-10]. The pozzolanic materials are more and more widely being used in contemporary buildings and structures because they not only can reduce the amount of cement consumed but also can enhance multiple properties of cement and concrete. Metakaolin, as one type of widely used materials with pozzolanic properties, is an aluminosilicate formed by calcining kaolin at a high temperature. The reason for the widespread use of metakaolin is that it has economic and technological advantages over cement and concrete, which reduces the hydration heat and thus the cost of production per cement unit $[11,12]$. Moreover, it has been reported that it has higher pozzolanic characteristics and reduces alkali-aggregate reactions [13-17]. However, due to its large particles 
and high agglomeration, metakaolin reduces the workability and mechanical properties of cement slurry and concrete, which causes the strength of the concrete mixed with metakaolin to be lower than that of the plain concrete [14].

In the past 20 years, nanomaterials, or rather particles with a diameter of smaller than $100 \mathrm{~nm}[18,19]$, have been studied in depth, especially for the improvement to cement and concrete products. Many studies have found that the addition of nanomaterials has a positive effect on the properties of concrete. Many types of nanomaterials used in concrete such as nano- $\mathrm{SiO}_{2}$, nano- $\mathrm{TiO}_{2}$, nano- $\mathrm{Al}_{2} \mathrm{O}_{3}$, and nano- $\mathrm{CaCO}_{3}[20-22]$ have been investigated in detail. The results demonstrate that the addition of nanomaterials improves the pore structure, the mechanical properties, and the durability of concrete [23-25]. Nanometakaolin (NMK) is a new type of nanomaterial, which has been applied to concrete during recent years. Compared with other nanomaterials such as nano- $\mathrm{TiO}_{2}$ and nano- $\mathrm{CaCO}_{3}$, nanometakaolin is more suitable for the enhancement of the mechanical properties and the durability of concrete. In this context, Shoukry et al. conducted ample research and proved that NMK can be used in Portland cement mortar, lightweight vermiculite cement composites, white Portland cement (WPC), high-volume ferrochrome slag mortar, and fiber-reinforced cementitious composites; they also studied the mechanical properties, thermal conductivity, capillary water absorption, and rheological properties of the prepared samples [26-28]. Amin et al. also reported that NMK can accelerate the rate of cement hydration and can optimize the pore structure of the hardened cement $[29,30]$. The work of Muhd et al. showed that NMK plays a positive role in ultrahigh performance concrete (UHPC) [31].

Due to the complex process and the high cost of production of nanomaterials, when they replace cement at a significant proportion, the cost of construction will greatly increase $[19,31,32]$. Therefore, although nanomaterials have the great ability to improve concrete, they cannot be widely used in practical engineering applications. As a result, producing metakaolin with a more reasonable particle size not only can be more easily used in engineering applications but also can significantly improve the cement-based materials. In this paper, the agglomerated particles of this metakaolin were controlled between 300 and $500 \mathrm{~nm}$ at most and according to the transmission electron microscopy (TEM) results. Since the particle size of the aggregate of this metakaolin ranges from $100 \mathrm{~nm}$ to $1.0 \mu \mathrm{m}$ [33], it is a submicron material [34-37]; this type of ultrafine metakaolin is named submicron metakaolin (SMK) in this work. Finally, with a simpler manufacturing process, submicron metakaolin has a slightly larger particle size than nanometakaolin.

In this paper, the submicron metakaolin, the agglomerated particle size of which was between ordinary metakaolin (MK) and NMK, was studied as an additive to the ordinary Portland cement slurry. The model of the surface water film of the SMK was established. The compressive strength and the flexural strength of the samples based on the SMK were measured and contrasted with those of the MK and the NMK obtained from the related literature
[38-40] at different curing periods. The microstructure and pore structure of the hardened cement slurry samples containing various percentages of the SMK were examined by the scanning electron microscopy (SEM) and mercury intrusion porosimetry (MIP). The effect of the SMK on the chemical composition of the cement slurries during hydration was studied by the thermogravimetric analysis (TGA). In short, the current work aims to investigate the effect of the SMK on the hydration process of the cementbased slurries and on the mechanical strength, pore structure, and microstructural characteristics of the hardened samples.

\section{Experimental Procedures}

2.1. Materials. Ordinary Portland cement (OPC) grade 42.5R was supplied by Dalian Onoda Cement Co. Ltd., China, and the ordinary metakaolin was obtained from Yangzhou Dilan Chemical Co. Ltd., China. In the author's lab, metakaolin was milled for $2 \mathrm{~h}$ (wet ball milling, a $75 \mathrm{~mL} /$ $100 \mathrm{~mL}$ ethanol solution as the solvent, rotation speed of $400 \mathrm{rpm}$, and ball-to-powder ratio of $5: 1$ ). Then, the metakaolin solution was heated at $750 \pm 10^{\circ} \mathrm{C}$ for $2 \mathrm{~h}$ for dehydroxylation. Dehydroxylation caused alumina and silica to become disordered. Metakaolin absorbs water and reacts with some water to form $\mathrm{Al}_{2} \mathrm{Si}_{2} \mathrm{O}_{5}(\mathrm{OH})_{4}$, which reduces the activity of metakaolin. The purpose of calcination metakaolin before use is to ensure its activity. Then it is screened using a sieve with apertures of $2 \mu \mathrm{m}$. Afterward, it was ultrasonicated in an aqueous solution. The average particle size of the SMK was approximately $20-50 \mathrm{~nm}$, and that of the agglomerated SMK was $300-600 \mathrm{~nm}$. The main chemical composition and the weight percentages of the cement and the SMK are shown in Figure 1. The transmission electron microscopy (TEM) was used to investigate the microscopic morphology of the SMK (Figure 2(a)), and the minerals of the SMK were analyzed by the X-ray diffraction (XRD) as shown in Figure 2(b). Distilled water was used for preparing the cement pastes, and a polycarboxylic acid superplasticizer was utilized as the water reducer.

According to the TEM image of the SMK shown in Figures 2(a) and 2(b), the size of a single particle of the SMK was about $20-50 \mathrm{~nm}$, but the size of the aggregate ranged from 300 to $600 \mathrm{~nm}$; thus, it was very difficult to disperse the SMK into aggregate of a smaller particle size. The peaks of the XRD pattern occurred at a $2 \theta$ angle in the range of $20-40^{\circ}$; the crystals were highly disordered $[27,29]$, and the minerals were mainly amorphous. Various crystallization forms of the minerals such as $\mathrm{Al}_{2}\left(\mathrm{Al}_{2.8} \mathrm{Si}_{1.2}\right) \mathrm{O}_{9.54}$, $2 \mathrm{Al}_{2} \mathrm{O}_{3} .2 \mathrm{SiO}_{2}$, and $\mathrm{Al}_{2.4} \mathrm{Si}_{0.6} \mathrm{O}_{4.8}$ were also seen (Figure 2(c)).

2.2. Sample Preparation. To examine the effect of the SMK on the cement slurry, the OPC was partially replaced by different proportions of the SMK, namely, 0, 1, 3, 5, and $7 \mathrm{wt}$ $\%$, as given in Table 1 . Consequently, five types of the specimens, the Portland cement of which was partially replaced by the SMK, were used in the experimentation. In order to compare the ratios of water to binder (the OPC plus 


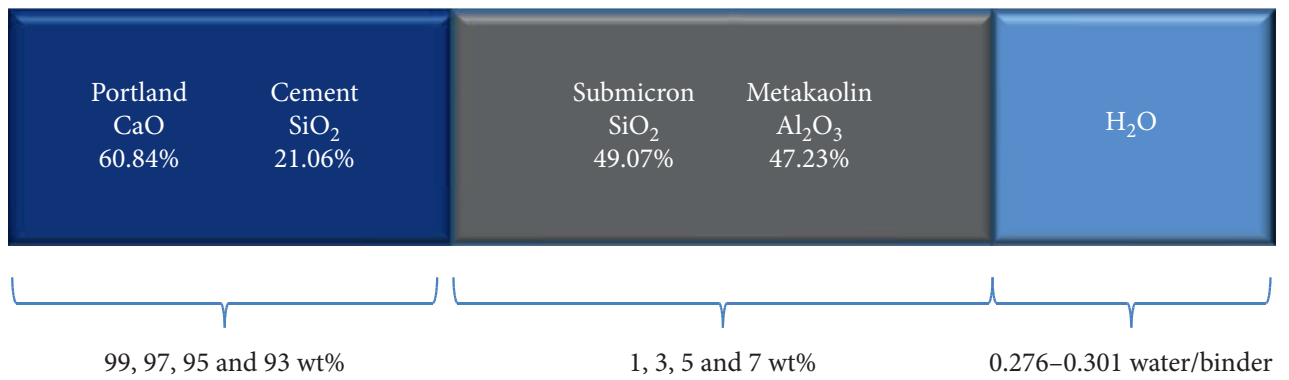

Figure 1: Chemical composition and weight percentages of the ordinary Portland cement and the SMK.
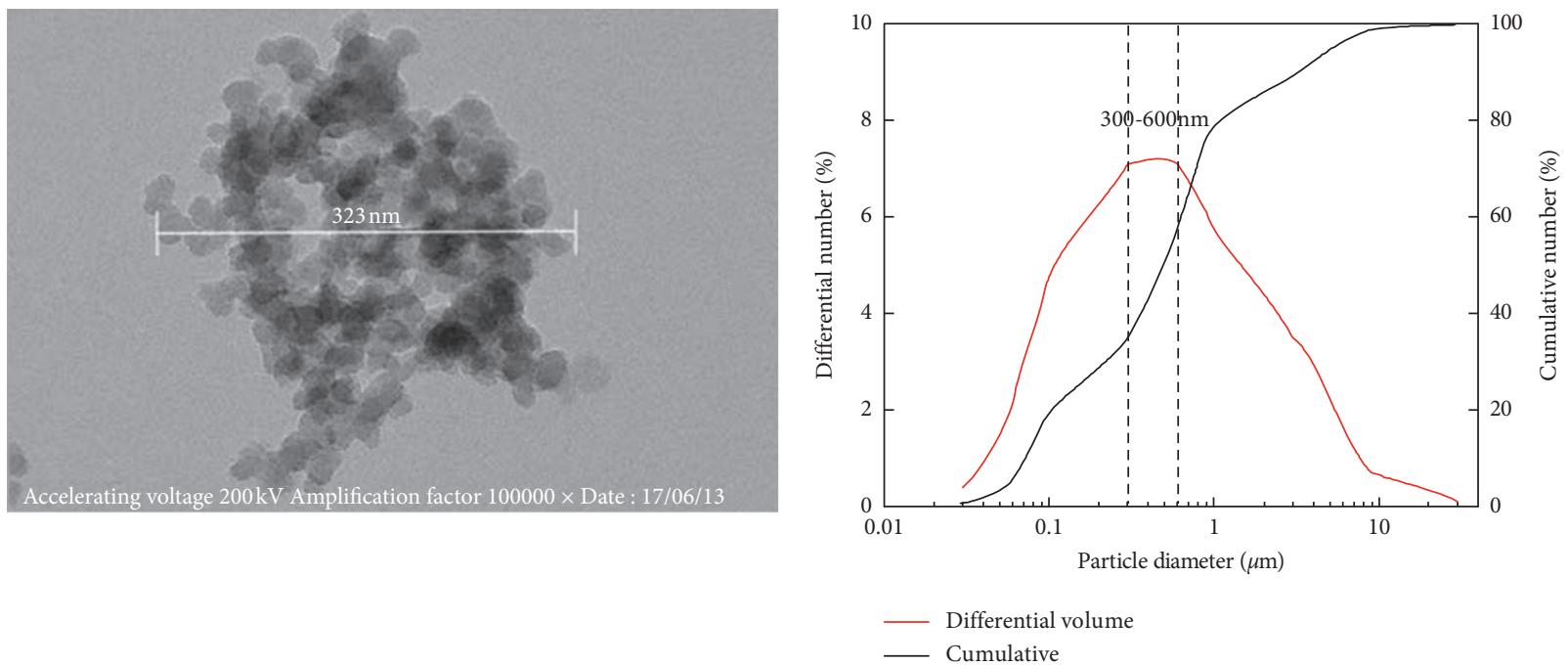

(a)

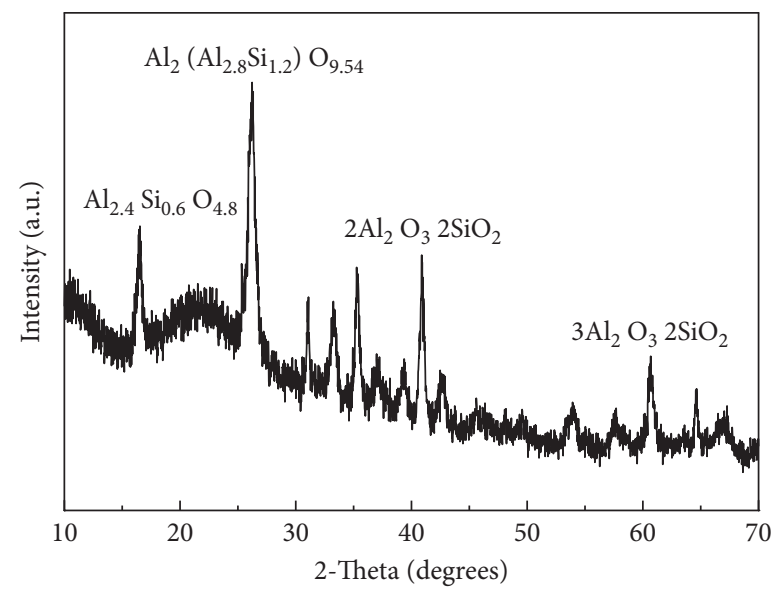

(c)

FIgURE 2: (a) The TEM image of the SMK; (b) particle size distribution of SMK; (c) the XRD pattern of the SMK.

the SMK) of the cement-based slurry (HCS) and find the optimal ratio, this paper adopts two methods to control the consistency: (1) the total mass of the SMK and the cement does not change, and the consistency is controlled by adjusting the mass of the mixing water; these samples are coded as NA\#, where \# indicates the weight percentage of the SMK. (2) The water-to-binder ratio is the same, and the consistency is controlled by adding various amounts of polycarboxylic acid water reducer (PAR); these specimens are coded as NB\#, where \# indicates the weight percentage of the SMK. Table 1 lists the mix proportions of these HCS designs.

In order to prevent the SMK particles from agglomeration and to evenly disperse the SMK in the HCS, the SMK and the water reducer were first added to water, and then the suspension was dispersed for $5 \mathrm{~min}$ using an ultrasonic 
TABle 1: Mix proportions of the HCS designs.

\begin{tabular}{lcccc}
\hline Mix & OPC $(w t \%)$ & SMK $(w t \%)$ & Water/(OPC + SMK $)$ & PAR/(OPC+ SMK) $(\%)$ \\
\hline N0 & 100 & 0 & 0.276 & 0.000 \\
NA1 & 99 & 1 & 0.280 & 0.000 \\
NA3 & 97 & 3 & 0.287 & 0.000 \\
NA5 & 95 & 5 & 0.294 & 0.000 \\
NA7 & 93 & 7 & 0.301 & 0.000 \\
NB1 & 99 & 1 & 0.276 & 0.250 \\
NB3 & 97 & 3 & 0.276 & 0.375 \\
NB5 & 95 & 5 & 0.276 & 0.500 \\
NB7 & 93 & 7 & 0.276 & 0.750 \\
\hline
\end{tabular}

dispersing device; next, the cement was added to the suspension, and the cement-based slurry was stirred at a low speed $(140 \pm 5 \mathrm{r} / \mathrm{min})$ for $120 \mathrm{~s}$ to fully mix all the materials; the mixing was stopped for $15 \mathrm{~s}$ to scrape the cement off the blender blades and mixing vessel walls; finally, the cementbased slurry was mixed at a high speed $(285 \pm 10 \mathrm{r} / \mathrm{min})$ for $120 \mathrm{~s}$.

Cubes with the dimensions $20 \mathrm{~mm} \times 20 \mathrm{~mm} \times 20 \mathrm{~mm}$ were cast for the analysis of the compressive strength, and prisms with the dimensions $160 \mathrm{~mm} \times 40 \mathrm{~mm} \times 40 \mathrm{~mm}$ were cast for the analysis of the flexural strength; all the cast specimens were demolded after $24 \mathrm{~h}$ and then cured under standard curing conditions at a temperature of $20 \pm 1^{\circ} \mathrm{C}$ and relative humidity of $95 \%$ for a curing period of $3,7,14$, and 28 days. We made six replicate samples to ensure the statistical reliability of the test results. The test specimens used for the TGA, MIP, and SEM were extracted from the center of the specimens employed for the analysis of the compressive strength.

2.3. Testing and Analysis Techniques. The mechanical strength and the microstructure of the hardened cementbased slurries containing various percentages of the SMK were studied by employing the following testing methods to understand the impact of the SMK on the hydration and hardening of the cement-based slurries.

2.3.1. Standard Consistency. According to standard GB/T $1346 \rightarrow 2011$, the cement-based slurry was then poured into a test mold placed on a glass bottom plate. To smooth the surface of the net cement paste, the excess net cement paste was removed and wiped. We quickly move the test mold and bottom plate to the Vicat apparatus, set the center of gravity on the test rod and lower the test rod until it comes into contact with the surface of the cement paste. After tightening the screw 1-2 s, we suddenly relax and make the test rod sink vertically into the cement slurry freely. Then, we record the distance between the test rod and the bottom plate at $30 \mathrm{~s}$ when the test rod is released. We take the test rod sunk to the net pulp $6 \mathrm{~mm} \pm 1 \mathrm{~mm}$ from the bottom plate as the standard consistency of the cement slurry. The amount of water used for mixing was calculated as a percentage of the mass of the total water required for the standard consistency of the cement paste.
2.3.2. Compressive Strength Analysis. The compressive strength tests were performed using YAW-300B compression machine which was controlled by computer (Figure 3); the speed of the movement of the top board was $0.05 \mathrm{~mm} / \mathrm{s}$. Every result of the compressive strength was reported as the average of the measurements carried out on six test cubes.

2.3.3. Flexural Strength Analysis. The specimens with the dimensions $160 \mathrm{~mm} \times 40 \mathrm{~mm} \times 40 \mathrm{~mm}$ were used for the flexural strength analysis using the same machine employed for the compressive strength testing. Six samples per batch were tested in accordance, and the average flexural strength of the six samples was reported.

2.3.4. Scanning Electron Microscopy and Energy Dispersive $X$-Ray Spectroscopy. The influence of the SMK on the microstructure of the hardened cement-based slurries was studied through analytical scanning electron microscopy, using an A JSM-6360LV stereo scanner. The acceleration voltage, the resolution, and the magnification of the scanner were $20 \mathrm{kV}, 10 \mathrm{~nm}$, and 50,000-350,000, respectively. The working voltage and the working current were set at $112 \mathrm{kV}$ and $5 \mathrm{~mA}$, respectively, and the spraying thickness was $20-30 \mathrm{~nm}$. Also, the energy dispersive X-ray spectroscopy (EDS) was utilized to investigate the phases and microstructural characteristics of the HCS. The HCS specimens were vacuum dried in an oven at a temperature of $50^{\circ} \mathrm{C}$ for $24 \mathrm{~h}$ before testing, and the fresh fracture surface of the samples was made conductive.

2.3.5. Thermogravimetric Analysis. The TGA was performed using TAQ600, in a temperature range of $30-800^{\circ} \mathrm{C}$, at a heating rate of $10^{\circ} \mathrm{C} / \mathrm{min}$, and in an atmosphere of nitrogen at a flow rate of $50 \mathrm{~mL} / \mathrm{min}$; the data recording interval was set at $0.5 \mathrm{~s}$, and the accuracy of the balance was $0.01 \mathrm{mg}$ [40]. At different periods of hydration, the samples tested were crushed into a powder and were soaked in isopropanol for $18 \mathrm{~h}$ in order to stop hydration; then, the samples were further ground into a fine powder. To ensure that the quantity of the free water in the cement slurry did not affect the calculation, before the measurements, the samples were oven-dried at a temperature of $105^{\circ} \mathrm{C}$ for $1 \mathrm{~h}$. 


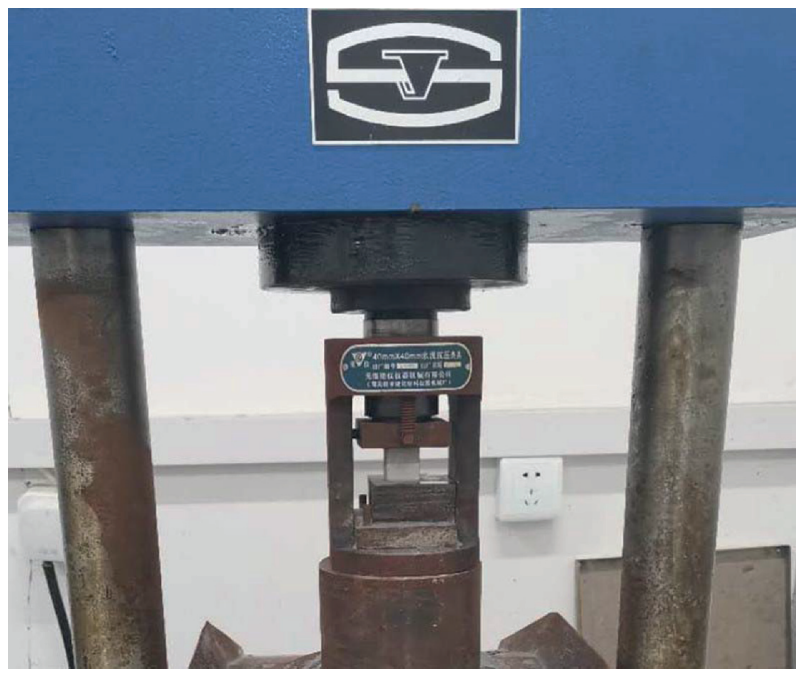

FIGURE 3: The cubes prepared for the compressive strength analysis and the YAW-300B compression machine.

2.3.6. Mercury Intrusion Porosimetry. The MIP was conducted on the samples using AutoPore IV 9500 mercury injection apparatus to examine the internal pore structure of the hardened cement-based slurries. The Mercury intrusion porosimetry measured the cumulative pore volume and the pore size distribution of the hardened cement pastes. In order to accurately characterize the pore structure, the cumulative pore volume of the samples was calculated by an integral method. The specimens were vacuum-dried in an oven at a temperature of $50^{\circ} \mathrm{C}$ for $24 \mathrm{~h}$ before testing.

\section{Results and Discussion}

3.1. Water Requirement for Standard Consistency. During the standard consistency test of the HCS specimens, we found that there was an approximately positive linear correlation between the water-to-binder ratio and the SMK content of the binder, as delineated in Figure 4. Moreover, this paper compared the water consumption of the slurries containing various amounts of the SMK with that of the plain slurry and found that the water consumption of the HCS increased linearly with the amount of the SMK added to the binder (Figure 5), indicating that although the proportion of the SMK and the cement changed, the water consumption of both remained unchanged. Based on this discovery, we attempted to calculate the thickness of the water film coated on the surface of the SMK particles as an innovative exploration.

The water consumption of the cement-based slurries containing different amounts of the SMK could be expressed by

$$
\omega_{i}=\left(1+\frac{\delta_{0}-\delta_{i}}{\delta_{0}}\right) \times \omega_{0},
$$

where $\omega_{i}$ is the water consumption of the HCS specimens containing different amounts of the SMK $(\mathrm{g})$ and $\delta_{i}(i=0,1$, 3,5 , and 7) represents the water-to-binder ratio at different dosages of the SMK.

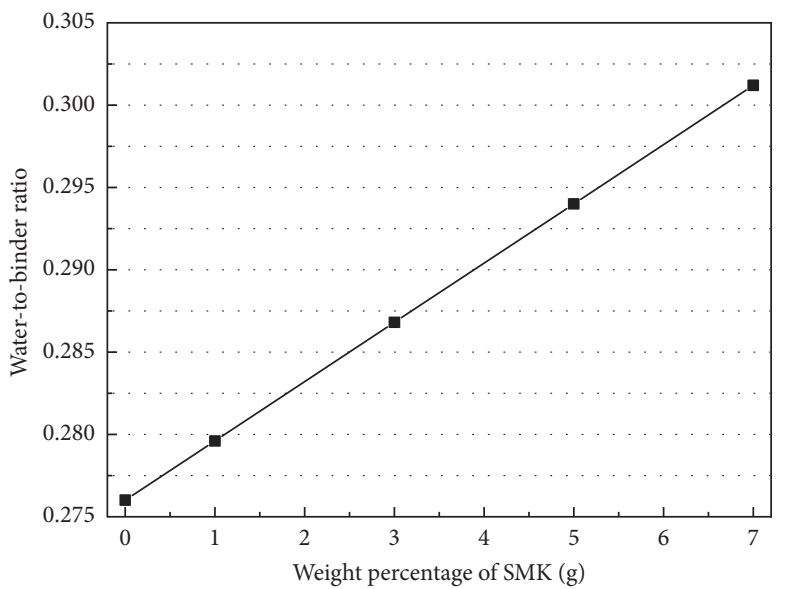

Figure 4: The relation between water-to-binder ratio and the weight percentage of the SMK.

The increment in the water consumption of the specimens containing different dosages of the SMK could be calculated by subtracting the water consumption of $\mathrm{N} 0$ from the water consumption of NA\# as expressed in

$$
\varpi_{i}=\omega_{i}-\omega_{0},
$$

where $\omega_{i}$ is the increment in the water consumption of NA\# with different dosages of the SMK $(\mathrm{g})$ and $\omega_{0}$ represents the water consumption of N0. Based on the geometric relationship between the amount of the added water and the amount of the SMK, as expressed in (3), the value of the slope of the relation $(k)$ between the water-to-binder ratio and the weight percentage of the SMK added to the binder was calculated as 0.36 .

$$
k=\frac{\varpi_{i}-\varpi_{0}}{\xi_{i}-\xi_{0}},
$$

where $\xi_{i}$ is the dosage of the SMK and $k$ is the slope of the linear relation in Figure 4. Dividing the value of the slope of 


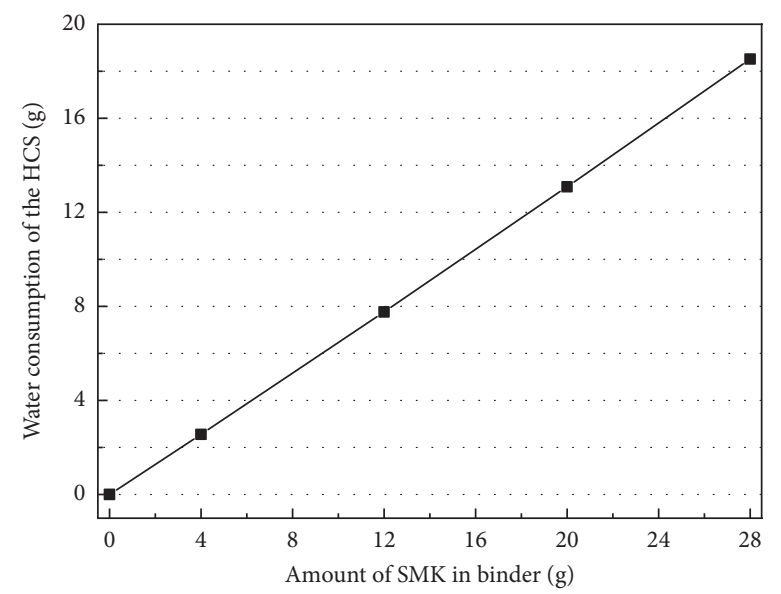

FIGURE 5: The relation between the water consumption of the HCS and the amount of the SMK added to the binder.

the relation by the water-to-binder ratio of the pure cement paste, as given by (4), resulted in a value of 1.304 , which indicated that the water absorption of the SMK at a standard level of consistency was 1.304 times that of the OPC 42.5R; further, it did not vary with the change of the SMK content of the binder:

$$
\alpha=k \cdot \frac{\omega_{0}}{\delta_{0}}
$$

where $\alpha$ is the ratio of the water consumption of the SMK to that of the ordinary Portland cement at a standard level of consistency. According to the SEM images, the average diameter of the SMK particles was usually about $50 \mathrm{~nm}$, so the density and water absorption of the SMK were used to figure out the volume of the water absorbed for a binder volume of $50 \mathrm{~nm}$ as expressed by

$$
V_{w}=\frac{\alpha \times(4 / 3) \pi R_{s}^{3} \times \rho_{s}}{\rho_{w}},
$$

where $V_{w}$ is the volume of the adsorbed water per volume of the SMK $\left(\mathrm{nm}^{3}\right) ; R_{s}(\mathrm{~nm})$ and $R_{w}(\mathrm{~nm})$ represent the radius of an SMK particle and the distance between the water surface and the SMK surface, respectively, and they are correlated by (6). By introducing the related values into the below equation, $R_{w}$ was calculated at $5.3 \mathrm{~nm}$.

$$
R_{w}=\sqrt[3]{\frac{V_{w}+(4 / 3) \pi R_{s}^{3}}{(4 / 3) \pi}}-R_{\mathrm{s}} .
$$

By substituting the relevant values into the sphere model, the resultant sphere model is illustrated in Figure 6.

The SMK had no free and bound water on its surface after being calcined at a high temperature before the experiments. When the SMK was mixed with water, water formed a film on its surface. When the water film was thin, after the SMK reaction, the remaining water could continue the hydration reaction with the cement to cause internal curing; nevertheless, when the water film was thick, large pores could be formed after the evaporation of the unreacted water, leading to the internal defects in the cement specimen. Submicron metakaolin particles are assumed to be spheres

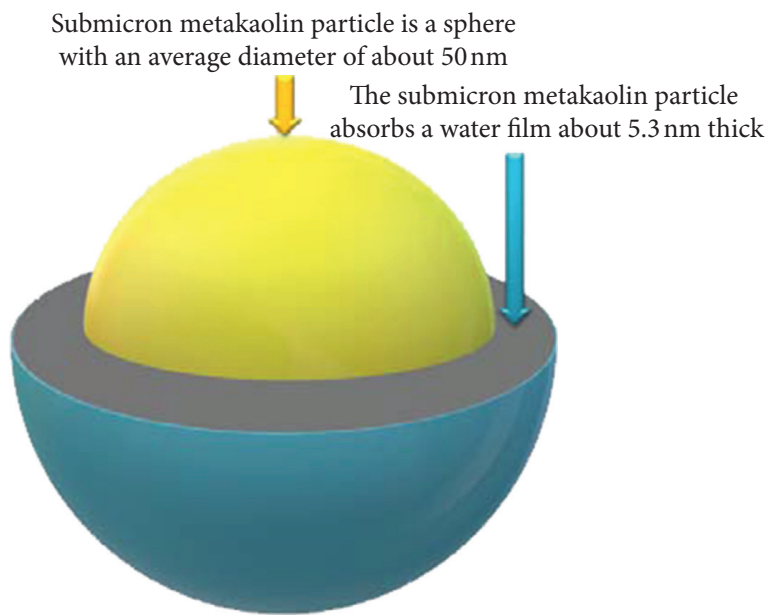

FIgURE 6: The sphere model of the SMK and water.

with an average diameter of about 50 nanometers. Submicron metakaolin particles absorb water to form a water film with a thickness of about $5.3 \mathrm{~nm}$.

\subsection{Mechanical Properties}

3.2.1. Compressive Strength of the HCS. The compressive strength of the HCS specimens containing different percentages of the SMK, namely, 1, 3, 5, and 7\%, at different curing periods of $3,7,14$, and 28 days is shown in Figure 7. The compressive strength of the HCS containing the SMK was higher than that of N0 at the same curing period. At the same SMK content of the HCS, the compressive strength of the "NB\#" specimens was generally higher than that of the "NA\#" specimens. For the samples without a water reducer, sample NA5 had the highest compressive strength. When the dosage of the SMK was lower than 5\%, the compressive strength of the HCS increased with the increase in the amount of the SMK. However, increasing the amount of the SMK to $7 \%$ reduced the compressive strength of the specimens significantly. At a high percentage of the SMK, the workability of the cement slurry decreased, and the SMK did 


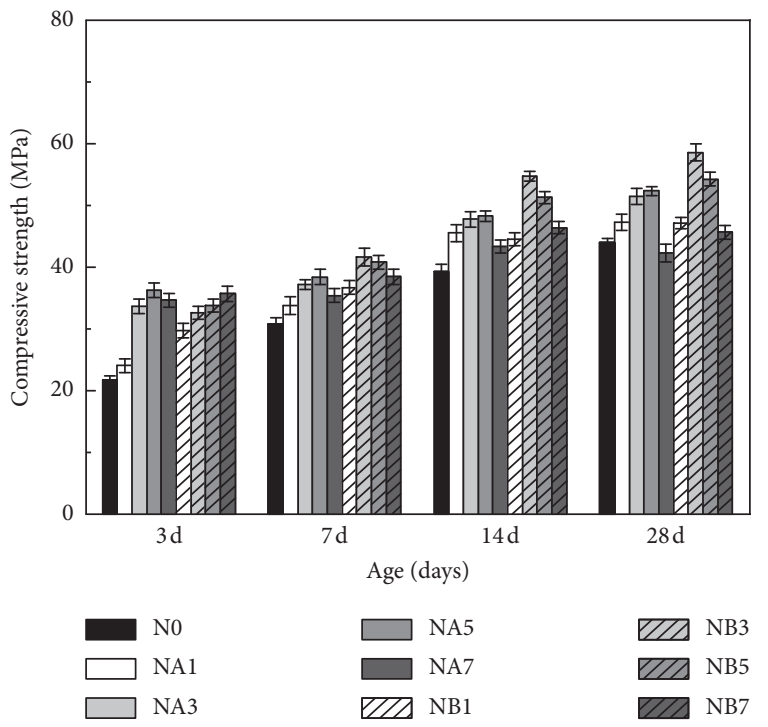

FIgURE 7: Compressive strength of the HCS samples at various curing periods.

not disperse sufficiently and agglomerated, which reduced the mechanical strength of the HCS. For the samples with the water reducer (NB), the HCS containing 3\% of the SMK (NB3) had the highest compressive strength. When the SMK content of the HCS exceeded 3\%, the compressive strength of the hardened samples continued to decline. Compared with the samples without a water reducer, the samples diluted with the water reducer were less suitable to contain a large amount of the SMK.

The HCS had the highest growth rate of the compressive strength at a curing period of 3 days, and the growth rate of the compressive strength of samples NA5 and NB3 was 67.27 and $50.14 \%$, respectively. This was mainly because the polycarboxylic acid water reducer decreased the water consumption of the HCS, and the cement hydration rate of sample NA5 was higher than that of sample NB3, causing the compressive strength of sample NA5 to be higher than that of sample NB3 at a curing period of 3 days. After 28 days of hydration, the growth rate of the compressive strength of samples NA5 and NB3 was 19.01 and 33.3\%, respectively, which was attributed to the fact that the SMK had a considerable water absorbency and could form a water film on the surface of its particles without a chemical reaction with water [27, 28]. Moreover, at a curing period of 28 days, the cement hydration was basically completed, and the water film could automatically break and form tiny pores, leading the compressive strength of sample NA5 to be lower than that of sample NB3.

3.2.2. Flexural Strength of the HCS. The flexural strength of the hardened cement-based slurries containing 1, 3, 5, and $7 \%$ of the SMK at different curing periods of 3, 7, 14, and 28 days is depicted in Figure 8. The flexural strength of the HCS specimens increased by extending the curing period when the dosage of the SMK was lower than 5\%. The flexural strength of the HCS specimens improved, and the growth rate of the flexural strength was almost concentrated in the

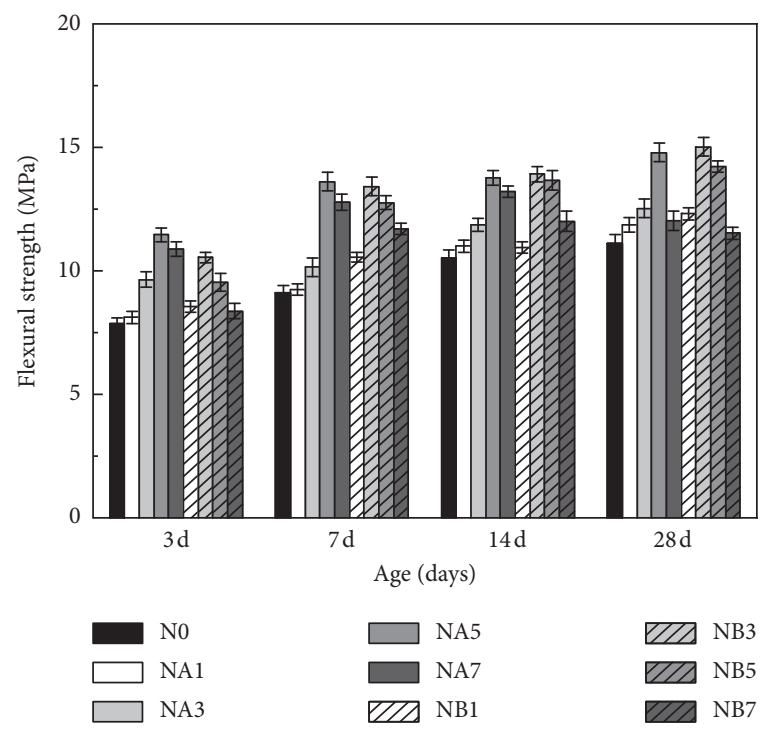

FIgURE 8: Flexural strength of the HCS samples at various curing periods.

early curing stage; the flexural strength of the hardened slurries grew relatively slowly after a curing period of 14 days. At a curing period of 3 days, the ultimate bending stress of samples NA5 and NB3 could reach 11.47 and $10.55 \mathrm{MPa}$, respectively, which were, respectively, about 46 and $34 \%$ higher than that of specimen N0. At a curing period of 28 days, the ultimate bending stress of specimens NA5 and NB3 could reach 14.80 and $15.02 \mathrm{MPa}$, respectively, which were, respectively, about 33 and $35 \%$ higher than that of specimen N0. These findings could be explained by the platelike structure of the SMK; in fact, it acted as a fiber among cement hydrates, bridging the microcracks in the cementitious matrix and providing resistance to crack propagation and crack opening before being pulled out [14]. In addition, the reaction of the aluminosilicate in the SMK 
with the calcium hydroxide formed the calcium-silicatehydrate (C-S-H) gel, which helped in creating a denser hardened cement paste.

\subsubsection{Comparison of Mechanical Properties with Data in the} Literature. Because the materials and the ratios used herein were not exactly the same as those reported in the related literature, to investigate the effect of the metakaolin of different particle sizes, the strength of the cement paste and cement mortar was compared with that of the plain cement or mortar.

The proportional increase in the compressive strength and the flexural strength of the SMK are compared to the data in the related literature in Figure 9. It is obvious that the addition of the SMK significantly improved the mechanical properties of the cement mortar compared to the MK. However, the mechanical strength of the cement mortar mixed with the SMK was lower than that of the specimen containing the NMK. This indicated that the activity of the SMK was significantly improved after further processing compared to the MK but was still lower than that of the NMK. Comparisons of our results with the works of Potapova and Dmitrieva [38] and AL-Salami et al. [39] demonstrated that the improvement in the flexural strength of the mortar by the MK, the SMK, and the NMK was higher than that in the compressive strength of the mortar, which implied that metakaolin of different particle sizes had a more positive effect on the flexural strength than on the compressive strength. The mechanical strength of the cement containing ordinary metakaolin hardly improved and even decreased. Compared to the plain cement, the compressive strength and the flexural strength of the cement containing submicron metakaolin increased by around $35 \%$, while those of the cement containing nanometakaolin improved by around $50 \%$ and even by approximately $60 \%$ as reported by Shoukry et al. [27, 28].

3.3. Microstructure Characteristics. The SEM images of samples N0 and NB3 at a hydration period of 3 and 28 days are illustrated in Figure 10. At a hydration period of 7 days, compared with sample N0, the CH crystal content of sample NB3 was more obvious, and its surface roughness was higher. At a hydration period of 28 days, there were still many $\mathrm{CH}$ crystals in specimen N0, while few $\mathrm{CH}$ crystals were visible in specimen NB3. The specimen surface was covered by a large number of $\mathrm{C}-\mathrm{S}-\mathrm{H}$ gels, and the intersections of the pores of sample N0 were significantly reduced. This indicated that the SMK could accelerate the formation of the $\mathrm{CH}$ crystals in a hydration period of 1-3 days due to its nucleating effect; nonetheless, at a curing period of 28 days, owing to its volcanic ash effect, it consumed a large number of the $\mathrm{CH}$ crystals in the HCS to form more C-S-H gels, which reduced the number of the pores of the specimen and increased its density. Because of its nucleating, filling, and pozzolanic effects, the addition of the SMK densified the cement-based slurry and therefore markedly enhanced the compressive strength and flexural strength of the HCS samples, as shown in Figures 7 and 8.
The SEM images and the EDS patterns of the internally unreacted submicron $\mathrm{SiO}_{2}$ and submicron aluminosilicate are presented in Figure 11. It can be seen that, at a curing period of 3 days, there were still unreacted submicron $\mathrm{SiO}_{2}$ and submicron aluminosilicate in specimen NB3. However, no obvious submicron $\mathrm{SiO}_{2}$ [27] and submicron aluminosilicate were found in sample NB3 at a curing period of 28 days. Therefore, we could infer that, at a curing period of less than 3 days, the SMK adhered to the HCS without an obvious pozzolanic effect [20], while when the $\mathrm{CH}$ crystal content of the HCS reached a certain concentration during a curing period of 3-28 days, the pozzolanic effect of the SMK gradually appeared [19]. To sum up, the pozzolanic effect of the SMK became noticeable when the concentration of the $\mathrm{CH}$ crystals reached a certain level. In this work, the pozzolanic effect of the SMK mainly materialized after 3 days of curing, while the increase in the mechanical properties of the hardened cement-based slurries before 7 days of curing was due to the nucleating and filling effect of the SMK.

3.4. Pore Size Distribution. For the analysis of the pore structure, sample NB3 with the highest mechanical performance was compared with sample N0 with the lowest mechanical properties. The differential curves of the pore size distribution of samples N0 and NB3 at a hydration period of 3 and 28 days are delineated in Figure 12. At the same hydration period, the total pore volume of sample NB3 was lower than that of sample N0. At a curing period of 3 days, the main pore diameter of sample NB3 ranged from 2000 to $20000 \mathrm{~nm}$ with a peak at around $4000 \mathrm{~nm}$, while that of sample N0 ranged from 2000 to $30000 \mathrm{~nm}$ with a peak at around $3000 \mathrm{~nm}$. According to the SEM images, the submicron $\mathrm{SiO}_{2}$ and submicron aluminosilicate had no significant pozzolanic effect during a hydration period of 3 days, so the decrease in the size of the pores was not due to the pozzolanic effect of the SMK [18]. In fact, the submicron $\mathrm{SiO}_{2}$ and submicron aluminosilicate were so tiny that they could fill the pores of the HCS, thereby highly decreasing the porosity of sample NB3 compared to sample N0. At a hydration period of 28 days, the main pore diameter of NB3 ranged from 3000 to $20000 \mathrm{~nm}$ with a peak at around $5000 \mathrm{~nm}$. On the other hand, the pore diameter of sample N0 was larger than $2000 \mathrm{~nm}$, and the main pore diameter ranged from 2000 to $30000 \mathrm{~nm}$ with a peak at around $3500 \mathrm{~nm}$, which indicated that the addition of the SMK could significantly reduce the number of the pores with a diameter of smaller than $5000 \mathrm{~nm}$.

The reason was that the particles of the SMK were small, and its nucleating effect could accelerate the rate of the cement hydration and could densify the HCS. At a hydration period of 28 days; the degree of the cement hydration was basically similar, while the volcanic ash effect of the SMK could transform more $\mathrm{CH}$ crystals into $\mathrm{C}-\mathrm{S}-\mathrm{H}$ gels, thereby reducing the porosity of the HCS [27].

3.5. Thermogravimetric Analysis. In the different HCS samples, the main mass change below $550^{\circ} \mathrm{C}$ was attributed to the mass loss caused by the release of $\mathrm{H}_{2} \mathrm{O}$ (dehydration) 


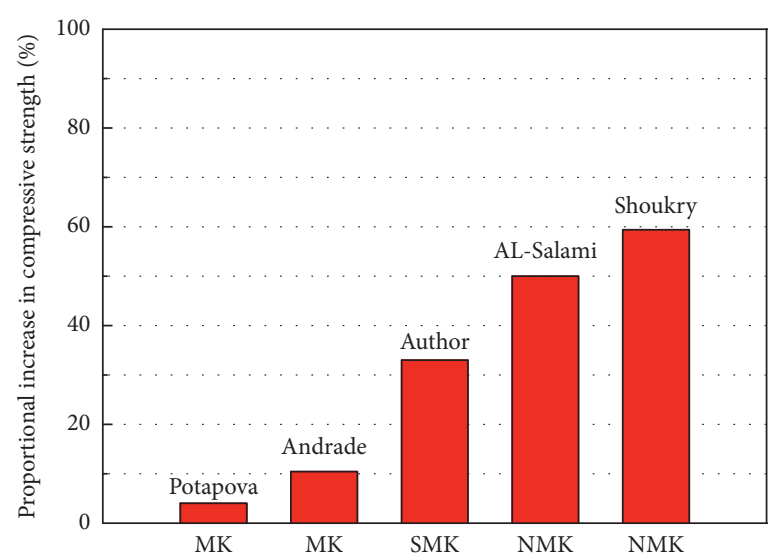

(a)

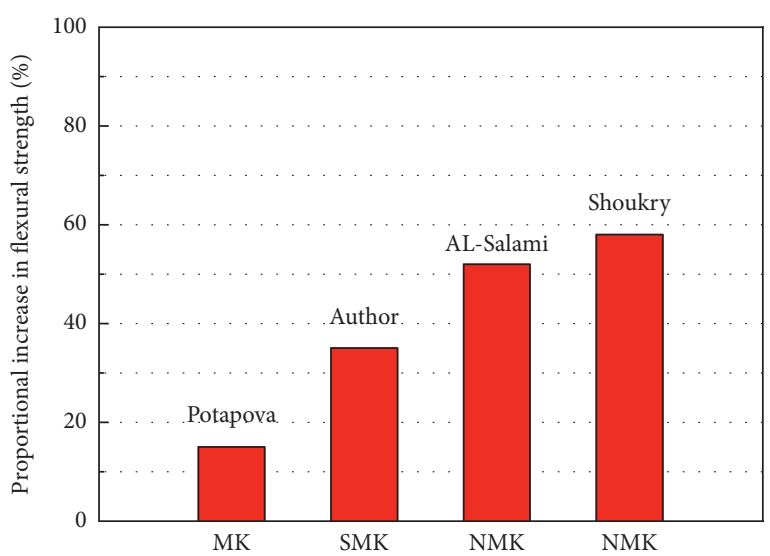

(b)

FIgURE 9: The proportional increase in (a) the compressive strength and (b) the flexural strength of the SMK compared to the data in the literature.

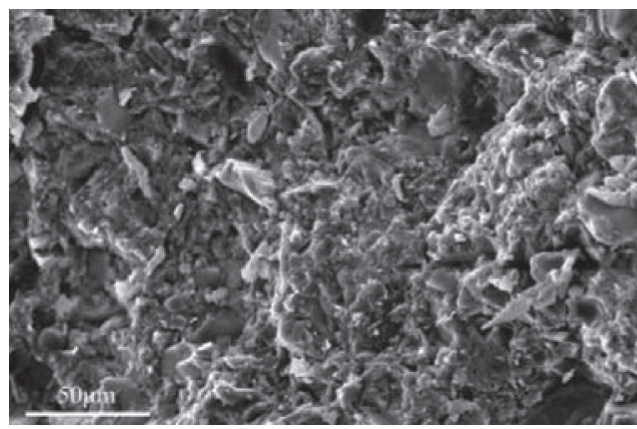

(a)

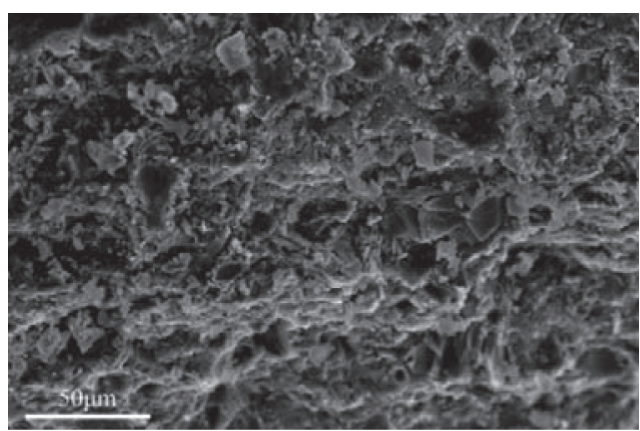

(c)

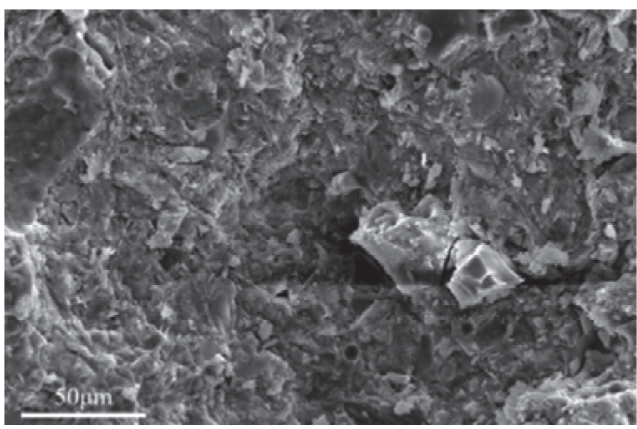

(b)

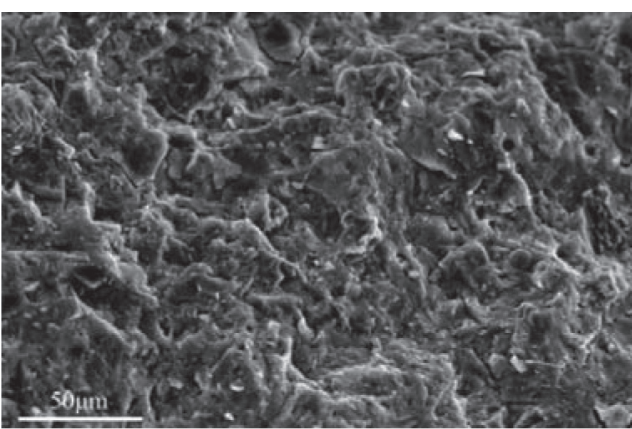

(d)

FIgUre 10: The SEM images of the HCS samples: (a) N0 at a curing period of 3 days; (b) NB3 at a curing period of 3 days; (c) N0 at a curing period of 28 days; (d) NB3 at a curing period of 28 days.

at low temperatures. Moreover, the peak of differential thermal analysis (DTA) curves at around $100^{\circ} \mathrm{C}$ was ascribed to the decomposition of the C-S-H gels and ettringite, and the peak in a temperature range of $400-500^{\circ} \mathrm{C}$ was due to the decomposition of the $\mathrm{CH}$ crystals [28].

The TGA and DTA curves of the samples at a curing period of 3 and 28 days are plotted in Figures 13(a) and 13(b), respectively. According to Figure 13(a), the percentage of the C-S-H gels and the $\mathrm{CH}$ crystals enlarged with the increase in the amount of the SMK at a curing period of 3 days. The SMK exhibited a nucleating effect and accelerated the rate of the cement hydration, thereby promoting the formation of the $\mathrm{CH}$ crystals and the C-S-H gels. As Figure 13(b) shows, the SMK could significantly increase the amount of the C-S-H gel and ettringite after 28 days of hydration, but the percentage of the $\mathrm{CH}$ crystals was not much different at a curing period of 28 days. Since the maximum loading of the SMK was only 7\%, the $\mathrm{CH}$ crystals 


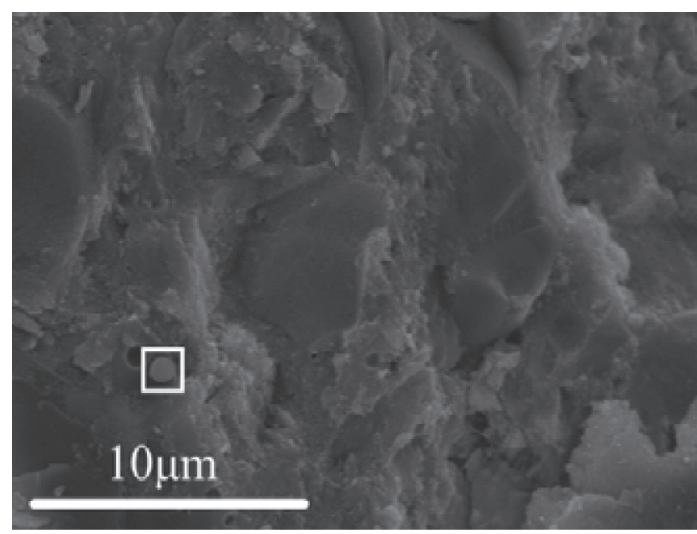

(a)

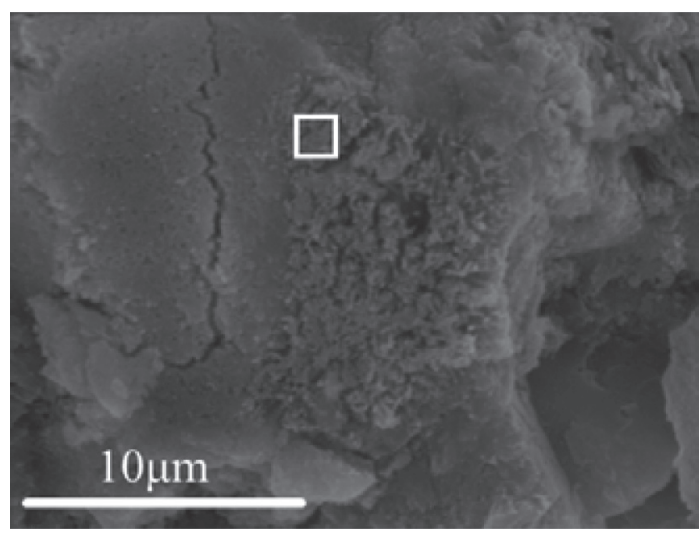

(c)

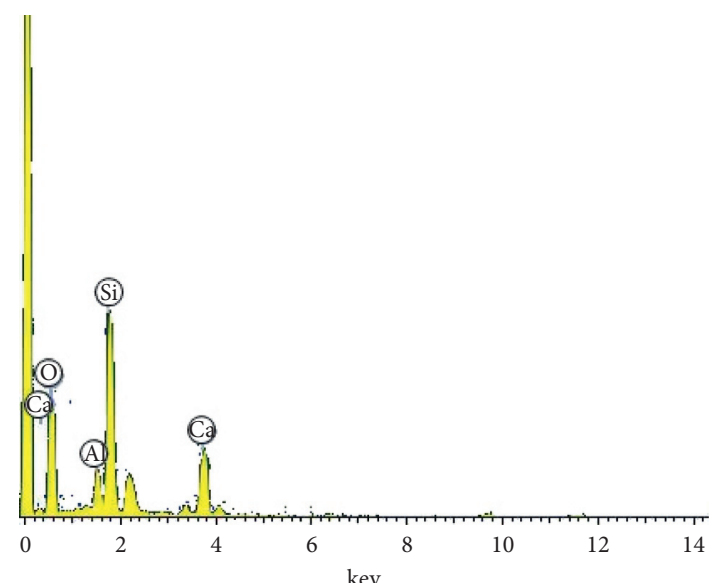

(b)

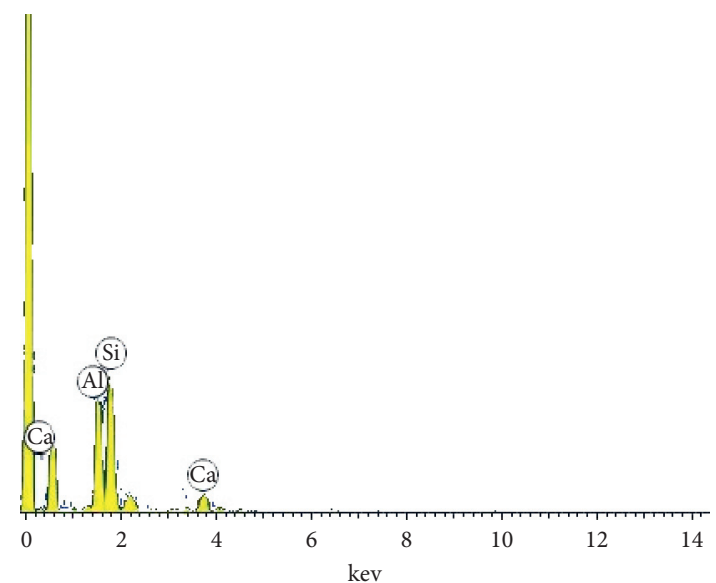

(d)

FIGURE 11: The SEM images and EDS patterns of submicron $\mathrm{SiO}_{2}$ and submicron aluminosilicate of the HCS at a curing period of 3 days: (a) SEM image of $\mathrm{SiO}_{2}$; (b) EDS pattern of $\mathrm{SiO}_{2}$; (c) SEM image of aluminosilicate; (d) EDS pattern of aluminosilicate.

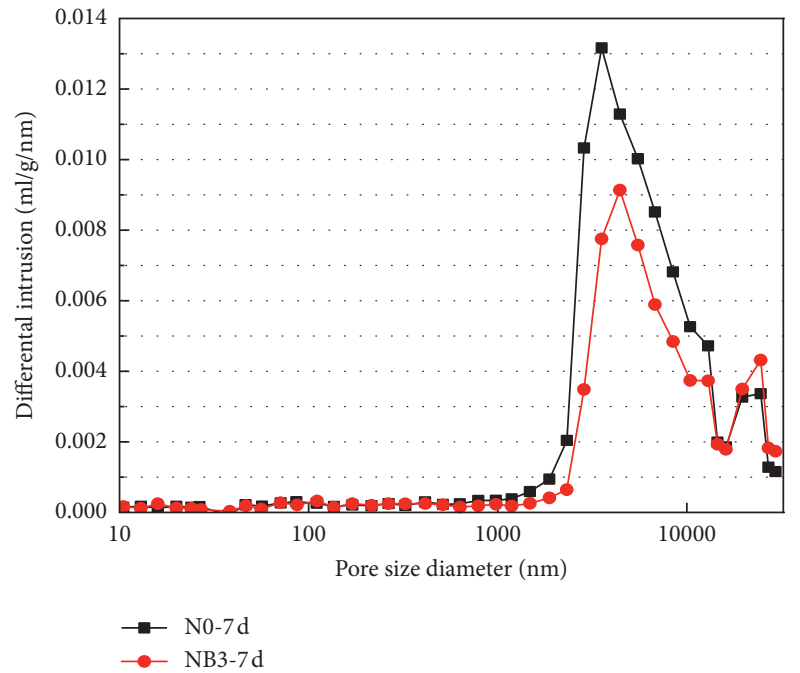

(a)

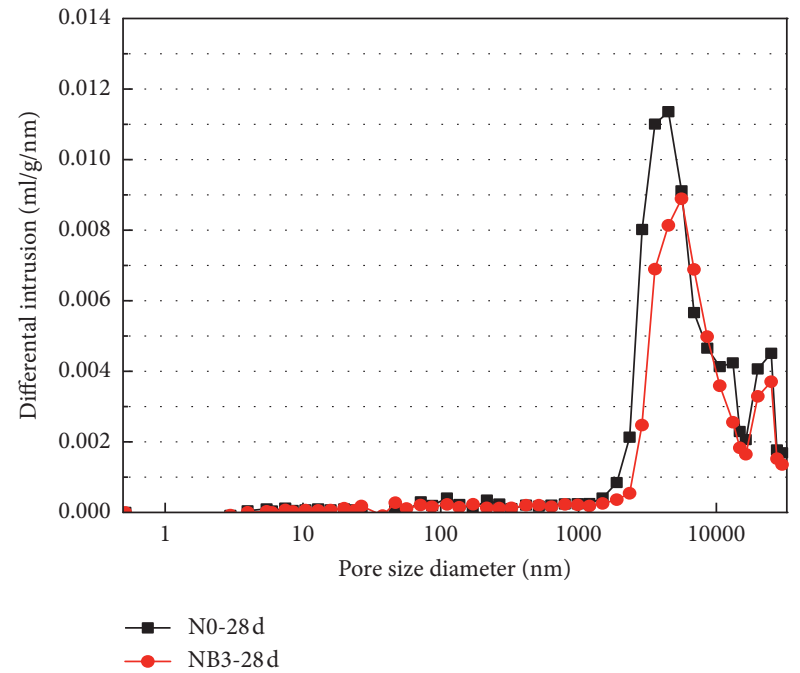

(b)

Figure 12: The pore size distribution of samples N0 and NB3 at a curing period of: (a) 3 days and (b) 28 days. 


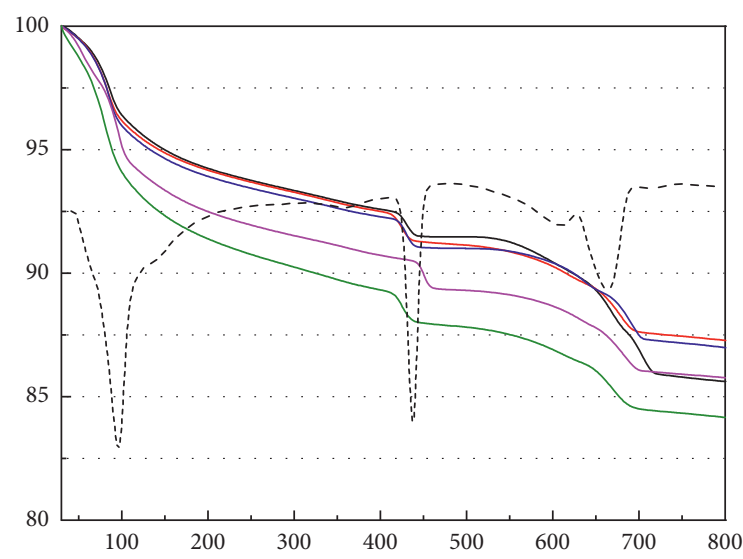

(a)

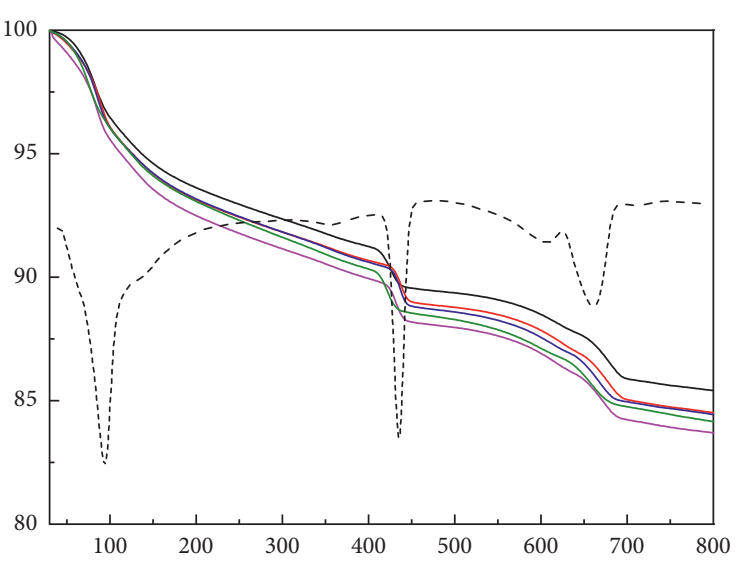

(b)

Figure 13: TGA and DTA curves of the HCS samples at a curing period of (a) 3 days and (b) 28 days.

could not be completely consumed, and when the concentration of the $\mathrm{CH}$ crystals declined to a certain value, the SMK could not continue to react with the $\mathrm{CH}$ crystals.

\section{Conclusions}

This paper investigated the impact of submicron metakaolin on the mechanical strength, pore structure, and microstructural characteristics of the hardened cement-based slurries. To this end, $1,3,5$, and $7 \%$ of the submicron metakaolin were added to the cement slurries. The main conclusions drawn from the findings of the current work are summarized as follows:

(1) In the early stage of the cement hydration, the nucleating effect of the submicron metakaolin accelerated the rate of cement hydration and cement hardening, played a regulating role in the growth of the cement hydration products, and promoted the formation of the $\mathrm{CH}$ crystals and the $\mathrm{C}-\mathrm{S}-\mathrm{H}$ gels. The compressive strength and the flexural strength of the HCS samples increased by more than 65 and $45 \%$, respectively, compared with those of the pure cement samples at a hydration period of 3 days.

(2) In the late stage of the cement hydration, the submicron metakaolin mainly had a pozzolanic effect, which reduced the number of the $\mathrm{CH}$ crystals in the HCS, increased the amount of the C-S-H gel in the HCS, and enlarged the density of the HCS samples. The compressive strength and the flexural strength of the HCS increased by more than 33 and 35\%, respectively, compared with those of the pure cement samples at a hydration period of 28 days.

(3) The TGA and MIP revealed that, in the early stage of the cement hydration, the unhydrated submicron metakaolin had a small particle size and could fill the internal pores of the cement pastes, thereby effectively reducing the pore diameter to smaller than $5000 \mathrm{~nm}$. In the late stage of the cement hydration, the submicron metakaolin reacted with the calcium hydroxide to form additional C-S-H gels, which further densified the microscopic pore structure of the cement pastes.

(4) By comparing the improvement in the mechanical properties of the cement paste or cement mortar, the impact of the metakaolin of different particle sizes, that is, nanometakaolin and submicron metakaolin, which are prepared under different process conditions, was studied. Finally, the findings of the current work can be used as a frame of reference for the methods of manufacture and applications of metakaolin in the future.

\section{Data Availability}

The data used to support the findings of this study are included within the article. The original data from Dr. Wang are all real data obtained from his own actual experiments. The pictures and words in the manuscript could fully prove the authenticity of his experiments.

\section{Conflicts of Interest}

The authors declare that they have no conflicts of interest.

\section{References}

[1] G. Moumin, M. Ryssel, L. Zhao et al., " $\mathrm{CO}_{2}$ emission reduction in the cement industry by using a solar calciner," Renewable Energy, vol. 145, pp. 1578-1596, 2020.

[2] Z. He, X. Zhu, J. Wang, M. Mu, and Y. Wang, "Comparison of $\mathrm{CO}_{2}$ emissions from OPC and recycled cement production," Construction and Building Materials, vol. 211, pp. 965-973, 2019.

[3] J. Ofosu-Adarkwa, N. Xie, and S. A. Javed, "Forecasting $\mathrm{CO}_{2}$ emissions of China's cement industry using a hybrid Verhulst-GM $(1, \mathrm{~N})$ model and emissions' technical conversion," Renewable and Sustainable Energy Reviews, vol. 130, 2020. 
[4] L. Proaño, A. T. Sarmiento, M. Figueredo, and M. Cobo, "Techno-economic evaluation of indirect carbonation for $\mathrm{CO}_{2}$ emissions capture in cement industry: a system dynamics approach," Journal of Cleaner Production, vol. 263, 2020.

[5] A. Cwirzen, L. Metsäpelto, and K. Habermehl-Cwirzen, "Interaction of magnesia with limestone-metakaolin-calcium hydroxide ternary alkali-activated systems," Advances in Materials Science and Engineering, vol. 2018, Article ID 1249615, 8 pages, 2018.

[6] V. M. Malhotra, "Fly ash, silica fume, slag and natural pozzolans in concrete," in Proceedings of the Third international conference on International Journal of Cement Composites and Lightweight Concrete, vol. 11, Trondheim, Norway, June 1989.

[7] H. Toutanji, N. Delatte, S. Aggoun, R. Duval, and A. Danson, "Effect of supplementary cementitious materials on the compressive strength and durability of short-term cured concrete," Cement and Concrete Research, vol. 34, no. 2, pp. 311-319, 2004.

[8] J. I. Escalante-Garcia and O. A. Martínez-Aguilarand, L. Y. Gomez-Zamorano, "Calcium sulphate anhydrite based composite binders; effect of portland cement and four pozzolans on the hydration and strength," Cement and Concrete Composites, vol. 82, pp. 227-233, 2017.

[9] M. M. Hossain, M. R. Karim, M. Hasan, M. K. Hossain, and M. F. M. Zain, "Durability of mortar and concrete made up of pozzolans as a partial replacement of cement: a review," Construction and Building Materials, vol. 116, pp. 128-140, 2016.

[10] M. Záleská, M. Pavlíková, Z. Pavlík et al., "Physical and chemical characterization of technogenic pozzolans for the application in blended cements," Construction and Building Materials, vol. 160, pp. 106-116, 2018.

[11] Y. Kocak, "Effects of metakaolin on the hydration development of portland-composite cement," Journal of Building Engineering, vol. 31, 2020.

[12] R. A. Sá Ribeiro, M. G. Sá Ribeiro, G. P. Kutyla, and W. M. Kriven, "Amazonian metakaolin reactivity for geopolymer synthesis," Advances in Materials Science and Engineering, vol. 2019, Article ID 8950764, 7 pages, 2019.

[13] S. Alonso and A. Palomo, "Calorimetric study of alkaline activation of calcium hydroxide-metakaolin solid mixtures," Cement and Concrete Research, vol. 31, no. 1, pp. 25-30, 2001.

[14] J. Cabrera and M. F. Rojas, "Mechanism of hydration of the metakaolin-lime-water system," Cement and Concrete Research, vol. 31, no. 2, pp. 177-182, 2001.

[15] K. Abdelli, M. Tahlaiti, R. Belarbi, and M. N. Oudjit, "Influence of the pozzolanic reactivity of the Blast Furnace Slag (BFS) and metakaolin on mortars," Energy Procedia, vol. 139, pp. 224-229, 2017.

[16] R. Siddique and J. Klaus, "Influence of metakaolin on the properties of mortar and concrete: a review," Applied Clay Science, vol. 43, no. 3-4, pp. 392-400, 2009.

[17] X.-Y. Wang, "Analysis of hydration and optimal strength combinations of cement-limestone-metakaolin ternary composite," Advances in Materials Science and Engineering, vol. 2019, Article ID 8361810, 13 pages, 2019.

[18] G. H. Barbhuiya, M. A. Moiz, and S. D. Hasanand, M. M. Zaheer, "Effects of the nanosilica addition on cement concrete: a review," Materials Today: Proceedings, vol. 32, pp. 560-566, 2020.

[19] D. M. T. Mustafa, S. Rostam, and S. B. Aziz, "A comparative study on structural, morphological, and tensile properties of binary and ternary epoxy resin-based polymer nanocomposites," Advances in Materials Science and Engineering, vol. 2020, Article ID 7914796, 11 pages, 2020.

[20] T. Ji, "Preliminary study on the water permeability and microstructure of concrete incorporating nano-SiO ${ }_{2}$," Cement and Concrete Research, vol. 35, no. 10, pp. 1943-1947, 2005.

[21] N. Farzadnia, A. A. Abang Ali, and R. Demirboga, "Characterization of high strength mortars with nano alumina at elevated temperatures," Cement and Concrete Research, vol. 54, pp. 43-54, 2013.

[22] J. Szymanowskiand and S. Łukasz, "Functional and adhesive properties of cement-based overlays modified with amorphous silica nanospheres," Journal of Adhesion, vol. 96, no. 14, pp. 207-228, 2020.

[23] P. Duan, C. Yan, W. Luo, and W. Zhou, "Effects of adding nano- $\mathrm{TiO}_{2}$ on compressive strength, drying shrinkage, carbonation and microstructure of fluidized bed fly ash based geopolymer paste," Construction and Building Materials, vol. 106, pp. 115-125, 2016.

[24] C. Moro, H. El Fil, V. Francioso, and M. Velay-Lizancos, "Influence of water-to-binder ratio on the optimum percentage of nano- $\mathrm{TiO}_{2}$ addition in terms of compressive strength of mortars: a laboratory and virtual experimental study based on ANN model," Construction and Building Materials, 2020.

[25] A. Hosan and F. U. A. Shaikh, "Influence of nano-CaCO addition on the compressive strength and microstructure of high volume slag and high volume slag-fly ash blended pastes," Journal of Building Engineering, vol. 27, 2019.

[26] M. S. Morsy, H. Shoukry, M. M. Mokhtar, A. M. Ali, and S. A. El-Khodary, "Facile production of nano-scale metakaolin: an investigation into its effect on compressive strength, pore structure and microstructural characteristics of mortar," Construction and Building Materials, vol. 172, pp. 243-250, 2018.

[27] H. Shoukry, M. F. Kotkata, S. A. Abo-EL-Enein, M. S. Morsy, and S. S. Shebl, "Enhanced physical, mechanical and microstructural properties of lightweight vermiculite cement composites modified with nano metakaolin," Construction and Building Materials, vol. 112, pp. 276-283, 2016.

[28] K. Al-Jabri and H. Shoukry, "Influence of nano metakaolin on thermo-physical, mechanical and microstructural properties of high-volume ferrochrome slag mortar," Construction and Building Materials, vol. 177, pp. 210-221, 2018.

[29] S. M. A. El-Gamal and M. S. Aminand, M. Ramadan, "Hydration characteristics and compressive strength of hardened cement pastes containing nano-metakaolin," HBRC Journal, vol. 13, no. 1, pp. 121-144, 2017.

[30] S. A. Abo-El-Enein, M. S. Amin, F. I. El-Hosiny, S. Hanafi, T. M. ElSokkary, and M. M. Hazem, "Pozzolanic and hydraulic activity of nano-metakaolin," HBRC Journal, vol. 10, no. 1, pp. 64-72, 2014.

[31] M. S. M. Norhasri, M. S. Hamidah, and A. M. Fadzil, "Inclusion of nano metaclayed as additive in ultra high performance concrete (UHPC)," Construction and Building Materials, vol. 201, pp. 590-598, 2019.

[32] N. P. Singh, "Properties of cementitious systems in presence of nanomaterials," Materials Today: Proceedings, vol. 29, pp. 1143-1149, 2020.

[33] J. Teizer, M. Venugopal, W. Teizer, and J. Felkl, "Nanotechnology and its impact on construction: bridging the gap between researchers and industry professionals," Journal of Construction Engineering and Management, vol. 138, no. 5, pp. 594-604, 2012. 
[34] K.-P. Yu, H.-C. Shih, Y.-C. Chen, and X.-E. Yang, "Effect of turbulence intensity and particle characteristics on the deposition of submicron particles enhanced by the ionic air purifier," Building and Environment, vol. 114, pp. 166-177, 2017.

[35] X. Li, Y. Liu, B. Liu, and J. Zhou, "Effects of submicron WC addition on structures, kinetics and mechanical properties of functionally graded cemented carbides with coarse grains," International Journal of Refractory Metals and Hard Materials, vol. 56, pp. 132-138, 2016.

[36] I. Izarra, J. Cubillo, A. Serrano, J. F. Rodriguez, and M. Carmona, "A hydrophobic release agent containing $\mathrm{SiO}_{2}$ $\mathrm{CH}_{3}$ submicron-sized particles for waterproofing mortar structures," Construction and Building Materials, vol. 199, pp. 30-39, 2019.

[37] M. Štefančič, A. Mladenovič, M. Bellotto, V. Jereb, and L. Završnik, "Particle packing and rheology of cement pastes at different replacement levels of cement by $\alpha-\mathrm{Al}_{2} \mathrm{O}_{3}$ submicron particles," Construction and Building Materials, vol. 139, pp. 256-266, 2017.

[38] E. Potapova and E. Dmitrieva, "The effect of metakaolin on the processes of hydration and hardening of cement," Materials Today: Proceedings, vol. 19, pp. 2193-2196, 2019.

[39] A. E. AL-Salami, M. S. Morsy, S. Taha, and H. Shoukry, "Physico-mechanical characteristics of blended white cement pastes containing thermally activated ultrafine nano clays," Construction and Building Materials, vol. 47, pp. 138-145, 2013.

[40] D. Da Silva Andrade, J. H. Da Silva Rêgo, P. Cesar Morais, and M. Frías Rojas, "Chemical and mechanical characterization of ternary cement pastes containing metakaolin and nanosilica," Construction and Building Materials, vol. 159, pp. 18-26, 2018. 